\title{
Implementation of a Performance Evaluation System for Nondestructive Testing Methods
}

\author{
Daniel Algernon*, Sascha Feistkorn, Michael Scherrer \\ SVTI - Swiss Association for Technical Inspections \\ Richtistrasse 15, 8304 Wallisellen, Switzerland \\ *Tel: +41448776 259 \\ *Email: Daniel.Algernon@svti.ch
}

doi:10.5296/jss.v2i2.10439

URL: http://dx.doi.org/10.5296/jss.v2i2.10439

\begin{abstract}
Nondestructive Testing (NDT) is an important means to ensure structural integrity and safe operation of components in many industries, as for example nuclear power plants, aerospace or civil engineering. Within the qualification of Nondestructive Testing personnel as well as validation of NDT procedures, practical demonstrations on test blocks with realistic flaws play a key role. Adequate test pieces need to be designed according to specific criteria such as quantity, shape, orientation, size and position of the test flaws, depending on the requirements of the national codes and standards in the specific industries. The performance of the candidates and inspection systems is quantified and analyzed with respect to criteria, such as detection, positioning, characterization as well as length and height sizing of flaws. Statistic measures are applied to express the resulting accuracy and overall performance. The indication reports obtained from different candidates contain ample information, which might not appear evident at first sight. The complexity of the situation requires an intelligent extraction of the information from the data. An analysis tool IndEva was developed to handle this complexity and provide an accurate, detailed and reliable evaluation of inspection systems and personnel. Besides the plain evaluation regarding the fulfilment of the qualification requirements, critical test flaws as well as test block sections, which are likely to cause false positive indications can be identified. Statistic results display the dependency of the system performance on various parameters and parameter combinations to provide a clear picture of the performance. Country-specific evaluation standards can be applied and compared, especially with regard to the continuous improvement of the qualification methodology.
\end{abstract}

Keywords: Nondestructive Testing and Evaluation (NDT, NDE), Performance Evaluation, Qualification, Nuclear Power Plants, Methodology Transfer 


\section{Introduction}

Nondestructive Testing (NDT) is applied in various industries to ensure quality and safety. Especially in the nuclear energy sector, safety is the primary focus. Failure of safety-relevant components can lead to severe hazards. This makes it necessary to implement effective processes ensuring a high level of safety and to establish safety quantification approaches.

A primary aspect of the safe operation of nuclear power plants is the structural integrity of safety-relevant components. Nuclear components are classified according to the safety standards (IAEA, 2014) of the International Atomic Energy Agency IAEA. To ensure the structural integrity, NDT methods are applied in in-service inspections (ASME, 2015) and play a key role in detecting, sizing and monitoring cracks and other flaws. If an inspection system does not capture an existing flaw correctly, this could affect the overall safety of a component and might pose a risk to system operation. Consequently, lack of reliability regarding the applied inspection techniques will affect the overall safety of a component. The high reliability requirements for NDT applications are met by the implementation of a qualification process, which inspections systems have to undergo.

In this respect, the term inspection system describes all elements of the inspection that can affect the inspection outcome, namely equipment, procedure (including inspection standards, if applicable) and personnel. The qualification process has to cover all these elements to evaluate the overall reliability. While different qualification systems have been established in different countries, qualification in European countries follows the methodology of the European Network of Inspection and Qualification (ENIQ) (The European Methodology for Qualification of Non-destructive Testing, Third Issue, 2007). Ultimately, the quantitative reliability-oriented results of the qualification process provide essential parameters in the quantification of the overall component safety, thus serving the goal of making safety measurable.

\section{Position of Nondestructive Testing regarding Safety and Safety Measures}

In the overall pursuit of ensuring a high level of safety and establishing quantitative measures for it (Figure 1, left), NDT can contribute significantly to component safety in terms of structural integrity. Structural integrity is evaluated based on fracture mechanical calculations, which need to take into account the actual component condition.

Since NDT inspection results provide an important decision basis (Erhard, 2007) regarding the safe operation of nuclear power plants, there are highly developed reliability-ensuring processes. Performance evaluation includes practical demonstration as well as theoretical assessment of the inspection system. Figure 1, right, shows the safety chain, along which the performance assessment based on practical trials as well as technical justification are linked to the overall goal of safe operation. They are important means to ensure the reliability of the information obtained from testing and evaluation with regard to the structural integrity. 


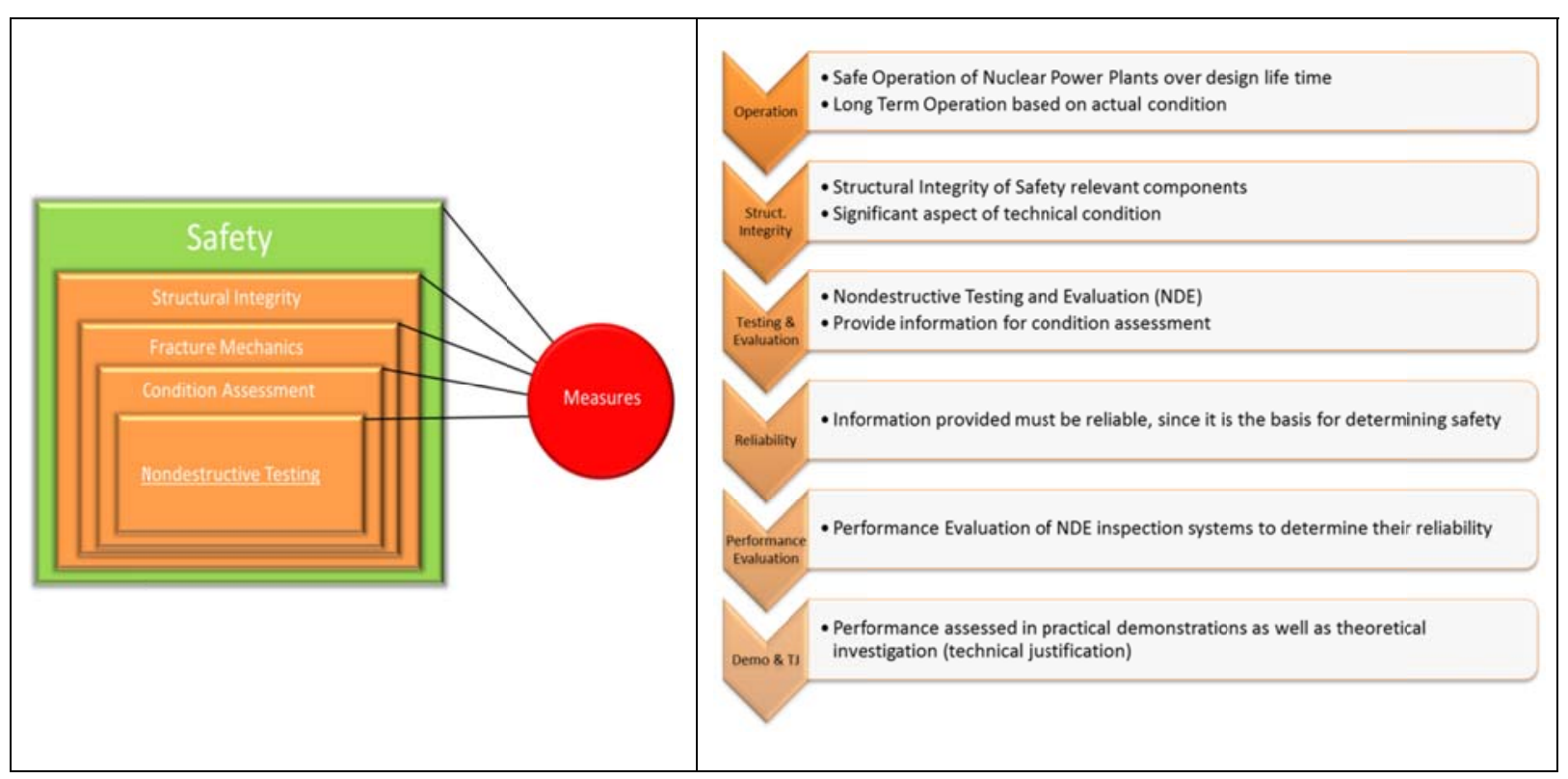

Figure 1. The position of NDT in establishing quantitative measures for safety in terms of structural integrity (left), and the role of performance evaluation of NDE inspection systems in ensuring safety in the nuclear energy industry (right)

\section{Key elements of Nondestructive Testing}

Figure 2 illustrates the process of nondestructive testing, in which key elements are linked following the overall goal of providing information about a component. Therefore, the value of the inspection can be quantified as the value of the information it provides. In order to be valuable, this information needs to be relevant and reliable.

NDT comprises the use of a physical principle, referred to as the NDT method, by means of adequate equipment in a certain way and using specific techniques, which is referred to as the procedure. This procedure is applied by personnel, which needs to be capable and trained. The inspection is conducted on a component (test object) with the goal of extracting information about the specific inspection target. Reliable functioning of the procedure implies that this procedure is valid for any test object as it is, with all its characteristics, such as material, geometry, surface condition, accessibility and environmental conditions.

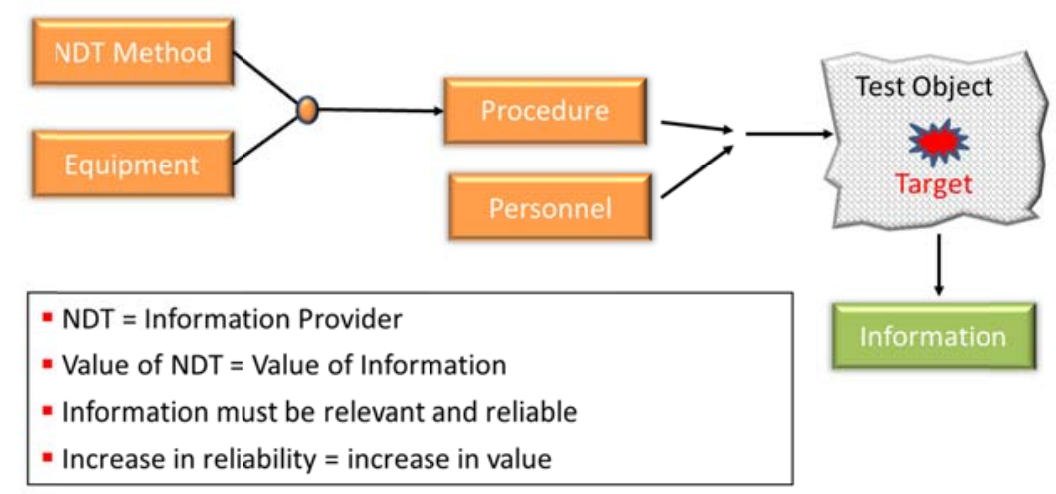

Figure 2. Elements in the process of nondestructive testing 


\section{Macrothink}

With the focus on safety-motivated NDT initiatives, the value of the inspection can be expressed as the increase in safety it provides. Regarding structural condition assessment, relevant information can be the detection and/or sizing of safety-relevant flaws, such as cracks. Lack of reliability (e.g. missing or undersizing existing cracks) would directly affect the reliability of the component regarding its structural integrity and therefore operatinal safety.

\section{Simulation of Testing Problems for Performance Optimization and Evaluation}

For procedure development, training of personnel and, ultimately, performance evaluation of an inspection system in a practical demonstration, the testing problem needs to be simulated by test targets (test flaws) placed in test blocks (Figure 3). The test block is supposed to provide response to the inspection system that are comparable to those obtained from the actual component. Test flaws can be actual flaws removed from the field and implanted in the test block or artificially fabricated test flaws.
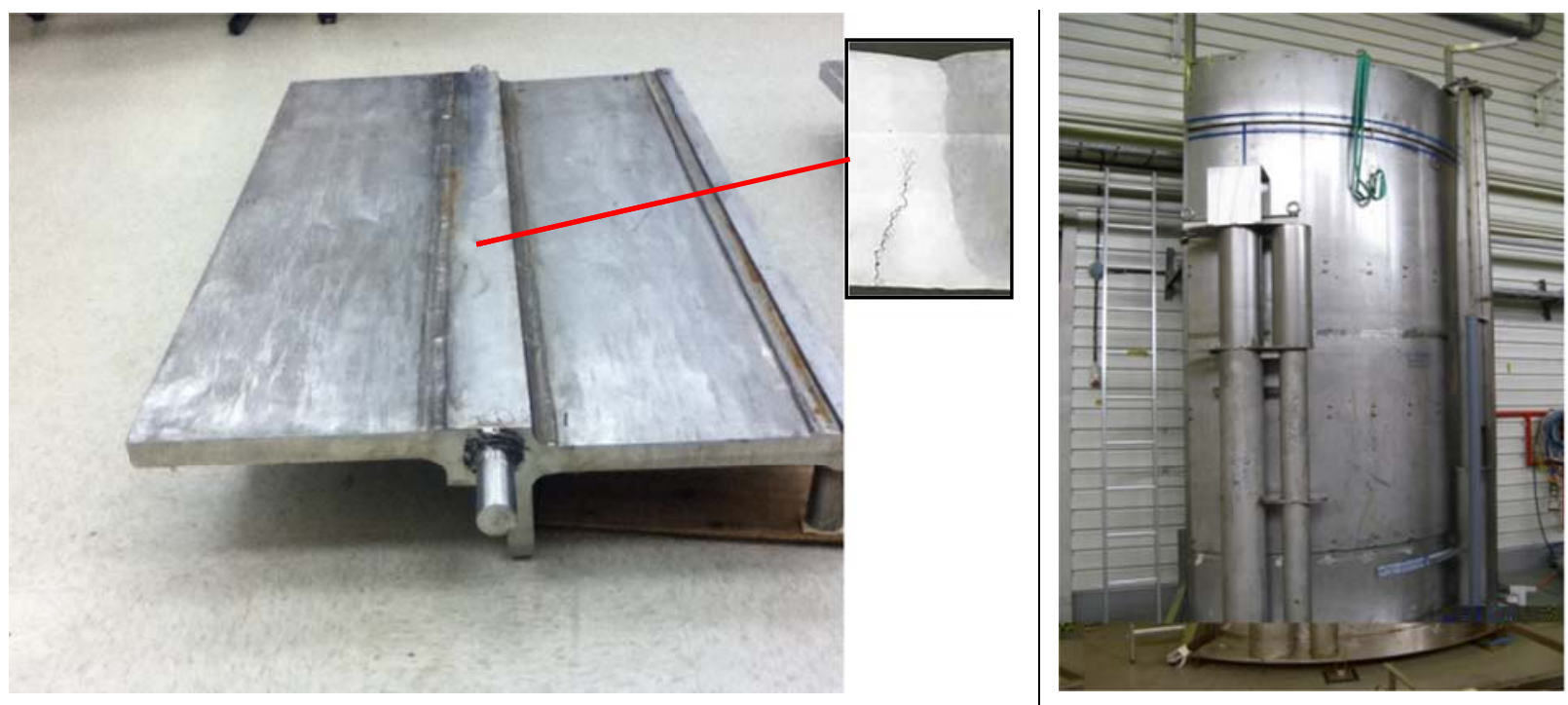

Figure 3. Example of test blocks used for component-specific qualification of an ultrasonic inspection system.

Left: Test block, realistically simulating the testing problem with regard to the ultrasonic inspection technique, made of the actual material, having the actual weld configuration and realistic test flaws.

Right: Full-scale mockup, realistically simulating the component geometry with regard to precise application of the inspection equipment, made of any material suitable for this purpose.

A thorough study of the flaw type and degradation mechanism on the one hand as well as an in-depth understanding of the testing method and signal characteristics is necessary to achieve the goal of realistic test flaws. Any uncertainty in the actual realization of the cracks will result in an uncertainty in the evaluation of the performance demonstration and will therefore limit the value of the qualification in general.

An example of a test block used for the component-specific qualification of an ultrasonic system is given in Figure 3. It represents a small portion of a cylindrical component of large diameter. This test block is made of the same material as the actual component and provides the 


\section{Macrothink}

same cross-sectional geometry as the actual component, including its welds. Realistic test flaws are implanted or artificially fabricated in the heat-affected zone of the welds.

The test block serves primarily to evaluate the performance of the ultrasonic inspection procedure. To ensure that the equipment can be properly operated in the actual field environment, full-scale mockups including all geometrical obtructions are used.

\section{Practical Demonstration}

The goal of the practical demonstration (Figure 4) is to prove that the inspection system is capable of solving the inspection task reliably in realistic conditions. To ensure sufficient reliability, the amount of samples (e.g. structural flaws investigated in the qualification, number of individuals demonstrating the procedure, etc.) needs to be statistically sufficient.
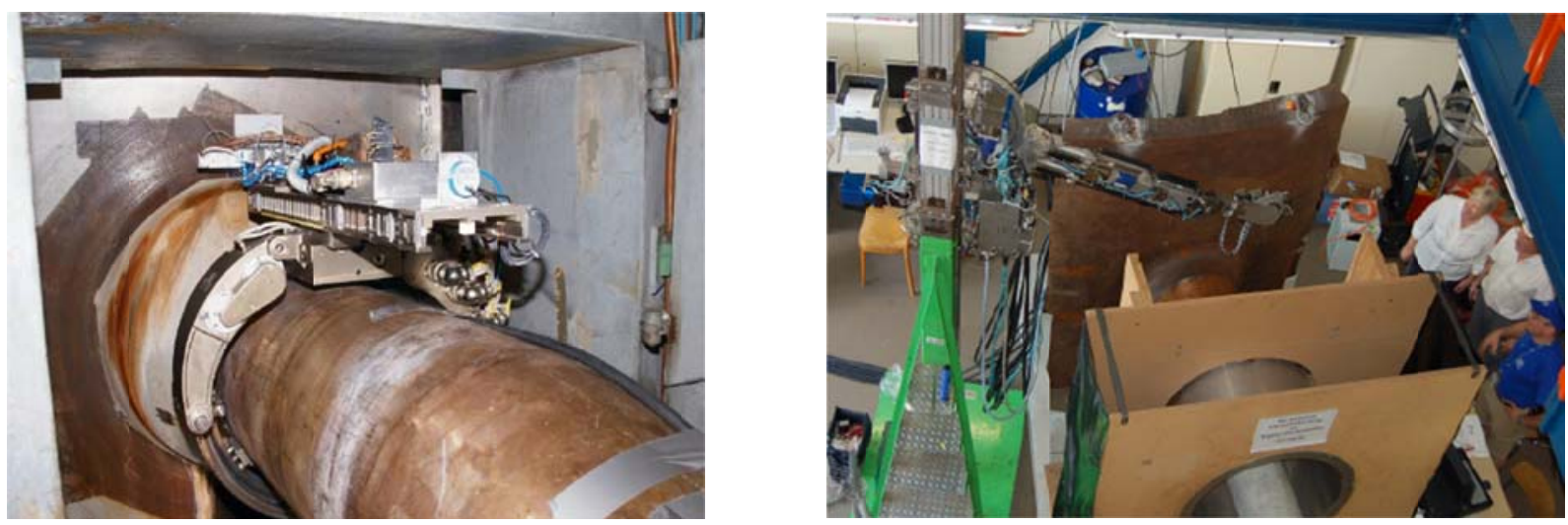

Figure 4. Reactor pressure vessel nozzle inspections on-site (left) compared to practical demonstrations in the qualification process (right).

\section{Characteristics of the ENIQ methodology}

\subsection{Assessment of the testing problem}

ENIQ methodology emphasizes the focus on the specific testing problem including the (postulated) flaw type. The relevant degradation mechanisms and resulting flaw types need to be determined. Experiences made under similar conditions need to be taken into consideration. To determine the relevant size of a defect that the inspection system needs to find reliably (qualification target), a fracture mechanic study is necessary. The potential growth of a flaw of the specific type needs to be taken into account and an adequate safety factor has to be applied.

\subsection{Assessment and simulation of the general conditions for the inspection}

For the practical demonstration to be representative of the field inspection, the relevant conditions need to be assessed and simulated. This can include limited accessibility of the component, under-water conditions (reactor pressure vessel), high temperature, time limitations, orientation of the test object or obstructions in the inspection area.

\subsection{Test blocks and targets (flaws)}

Since ENIQ qualification is component- and flaw type specific, it requires thorough assessment of the postulated flaw. A qualification target is defined as the basis for the 
qualification. Normally, this will be the smallest flaw size required to be detectable. The qualification target has all characteristics according to the postulated flaw mechanism.

\subsection{Technical Justification (TJ)}

Besides the practical demonstration, ENIQ qualification includes the use of technical justification (TJ). This means a theoretical assessment of the inspection system functionality by experts. For instance, it can be established by modeling and simulation of the inspection problem and technique (Calmon, Mahaut, Chatillon, \& Raillon, 2006).

\section{Quantitative Evaluation of Inspection System Performance in Practical Demonstrations with the Evaluation Tool IndEva}

The findings reported by candidates in practical demonstrations are evaluated regarding their match with the information about the actual test block condition. The performance of the candidates and inspection systems is quantified and analyzed. Statistical measures are applied to express the resulting accuracy and overall performance. The complexity of the situation requires an intelligent extraction of the information from the data. The software tool IndEva (Figure 6) evaluates at four different levels (Figure 5), focusing on different objectives (IndEva User Manual, 2014).

\begin{tabular}{|c|c|c|c|c|c|c|c|}
\hline \multicolumn{4}{|c|}{ Evaluation 1: Test Set/Candidate } & \multicolumn{4}{|c|}{ Evaluation 2: Candidate } \\
\hline & Kandidat 1 & Kandidat 2 & Kandidat 3 & & Kandidat 1 & Kandidat 2 & Kandidat 3 \\
\hline Testset 1 & $\mathrm{x}$ & & $\mathrm{x}$ & Testset 1 & $\mathrm{x}$ & & \begin{tabular}{|l|}
$\mathrm{x}$ \\
\end{tabular} \\
\hline Testset 2 & & $x$ & & Testset 2 & & $x$ & \\
\hline Testset 3 & $x$ & & & Testset 3 & $x$ & & \\
\hline Testset 4 & & $x$ & $x$ & Testset 4 & & $x$ & $x$ \\
\hline \begin{tabular}{|l|l}
$\cdots$ \\
\end{tabular} & & & & \multicolumn{2}{|l|}{$\cdots$} & & \\
\hline & Kandidat 1 & Kandidat 2 & Kandidat 3 & & Kandidat 1 & Kandidat 2 & Kandidat 3 \\
\hline Testset 1 & $\mathrm{x}$ & & $x$ & Testset 1 & $x$ & & $\mathrm{x}$ \\
\hline Testset 2 & $\square$ & $x$ & 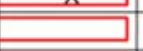 & Testset 2 & & $x$ & \\
\hline Testset 3 & $x$ & & & Testset 3 & $x$ & & \\
\hline Testset 4 & ᄃ & $\bar{x}$ & $x$ & Testset 4 & & $x$ & $x$ \\
\hline$\cdots$ & & & & \begin{tabular}{l|l}
$\cdots$ & \\
\end{tabular} & & & \\
\hline \multicolumn{4}{|c|}{ Evaluation 3: Test Set(Test Flaw) } & \multicolumn{4}{|c|}{ Evaluation 4: All Test Setsi (Procedur } \\
\hline
\end{tabular}

Figure 5. Evaluation Levels in IndEva

The first level is the individual evaluation of the reported candidate findings (indication list) for a specific test set (Figure 6, top right). The second level is the evaluation of the individual candidate in relation to all test sets that have been assigned to this candidate, thus revealing the performance of the individual candidate (Figure 7). The third level is the evaluation of each individual test flaw, taking into account the findings of all candidates, to whom this flaw has been assigned, thus revealing the capabilities of the procedure regarding each specific flaw. Finally, the fourth level of evaluation is taking into account all flaws and all candidates, thus revealing the overall performance of the procedure including the identification of critical flaws as well as areas with accumulations of false-positive indications (Figure 8). 

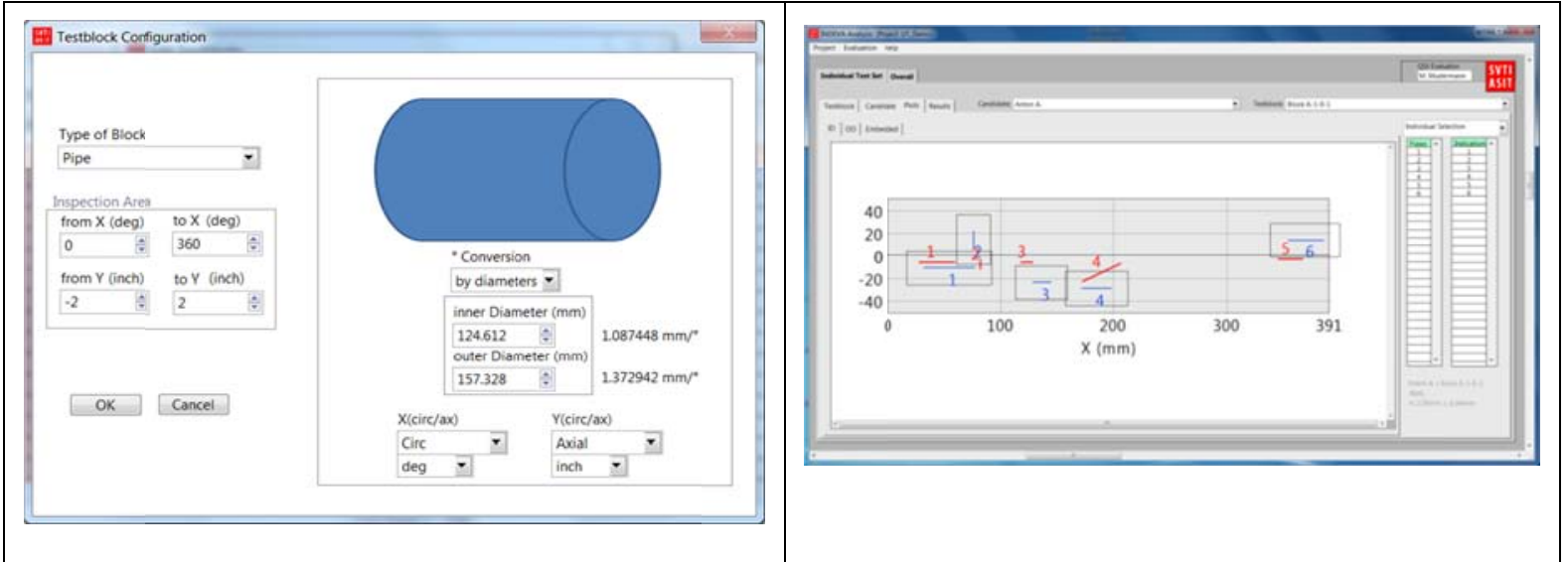

Figure 6. User Interface, selected examples

Top left: test block designer

Top right: Evaluation 1, test set/candidate, detection: graphic display of actual flaw position (according to as-built information) and reported indication (according to candidate report)

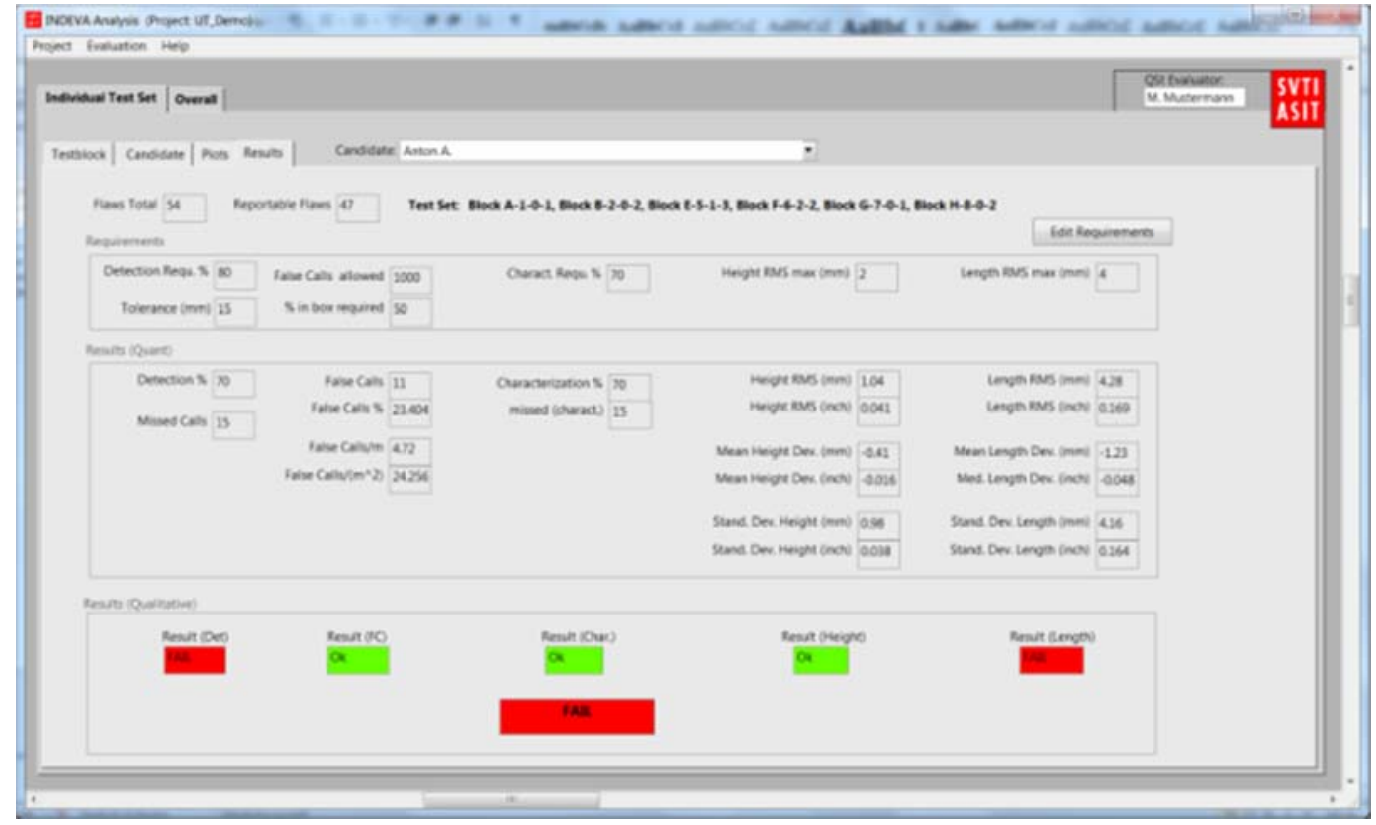

Figure 7. Evaluation 2, candidate, overall: quantitative results on candidate performance regarding evaluation criteria detection, false calls, characterization, heightt sizing and length sizing, taking into account all test sets assigned to the specific candidate. 


\section{Macrothink}

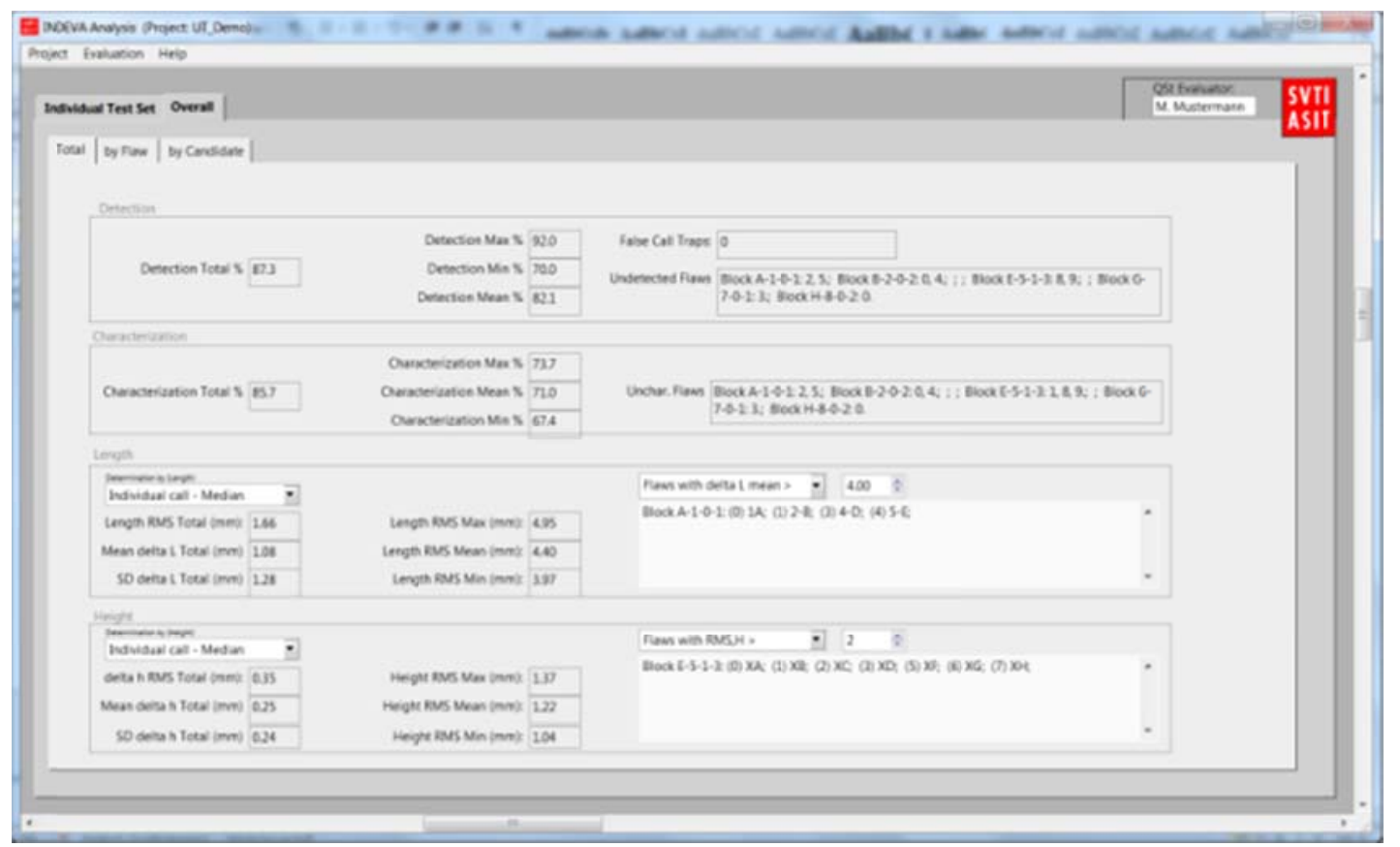

Figure 8. Evaluation 4, procedure, overall: quantitative results on procedure performance regarding evaluation criteria detection, false calls, characterization, height sizing and length sizing, taking into account all test sets assigned to all candidates.

At each level, the evaluation includes detection percentage, missed flaws, thru-wall sizing, length sizing and the amount of false-positive findings. Results can be expressed in different statistical terms (RMS; standard deviation, mean, median, max, min,...) and units. Pass/Fail criteria can are defined at all levels. The evaluation serves in quantifying the performance of all inspection system elements with the ultimate goal of the expressing quantitative measures for the reliability of the inspection system.

\section{Quantification of Technical Justification within the Qualification Process}

To establish an adequate (statistical) level of confidence, practical demonstrations need to include a sufficient number of samples. However, an important confidence building aspect of the qualification is not only the number of practical trials, but especially the thorough theoretical assessment conducted by knowledgeable and experienced technical experts. Within the ENIQ methodology, this theoretical assessment is documented in the technical justification (TJ). In particular, the use of modeling and simulation tools, such as semi-analytical computation software (Calmon, Mahaut, Chatillon, \& Raillon, 2006) can provide valuable information and help in making the qualification process effective and efficient.

Since the fabrication of realistic test blocks and test flaws is a very complex and expensive process, the number of samples used in practical demonstrations will be limited, thus resulting in limited statistical confidence. High confidence can still be achieved by having the inspection system investigated by experts. Usually, this is not covered by the numerical expression result obtained from the practical demonstration on the samples. On the one hand, this would result in underestimation of the confidence level of the qualification and therefore the resulting 
reliability of the inspection system. However, on the other hand, purely relying on the numerical result of the practical demonstration alone could bear the risk of missing flaws with regards to very specific flaw positions, shapes or sizes, which are not included in the samples of the practical demonstration. A deeper theoretical understanding of the inspection system will be necessary to grasp these specific cases and accurately evaluate the reliability of the inspection system.

The relevance of technical justification in the qualification process being identified, the need to include it in the quantitative expression of the qualification outcome becomes evident. To express technical justification quantitatively, an approach has been introduced in Gandossi \& Simola (2007) based on Bayesian statistics. A key aspect of this approach is the expression of meaningfulness of the TJ as an equivalent number of practical trials $N_{T J}$ and the result of the TJ regarding the performance of the inspection system as an equivalent number of successful trials $N_{T J, s}$ Naturally, such expressions require detailed and adequate criteria to determine these numbers.

\section{Addressing Different International Qualification Standards}

Compatibility of qualification systems is needed when inspection systems are transferred to application in a different country (Dressler, Ernst, Scherrer, \& Trautmann, 2012). To avoid redundancy, the demonstrated scope needs to be investigated with regard to acceptance and the resulting confidence level. Due to different requirements and also the component-specific focus of qualifications, the existing qualification will often need to be complemented by additional demonstrations and theoretical considerations.

The tool IndEva makes it possible to analyze the distribution of flaws in test sets regarding predefined criteria, which can be adapted to the specific needs. Furthermore, the statistical performance evaluation can be expressed according to the country-specific requirements. Based on the qualification standards, it is also possible to take into account and quantify the outcome of technical justification according to the approach explained in section 8 .

\section{Methodology Transfer to Other Industries: Example Civil Engineering}

While adavanced NDT has a long tradition in the nuclear energy industry, there are newer applications for NDT, as for instance NDT in civil engineering (NDT-CE), especially when applied on concrete structures. While in the past there was a primary focus on the research and development of capable inspection methods, techniques and prototype equipment, the number of commercial devices and applications is currently increasing. Consequently, the range of users and inspection problems is becoming wider and the demand for the quantification of inspection reliability is growing.

Quality assurance and qualification standards established in the nuclear industry can generally be used for civil engineering applications as well. However, for the methodology transfer to serve its purpose (Jolly \& Creighton, 1977), be efficient, and gain acceptance in the new industry, it needs to take into account the specific practices, needs and resources there.

Validation centers (Figure 9) have been initiated, in which the performance evaluation studies are conducted (Algernon, Hiltunen, Ferraro, \& Ishee, 2011). The optimization of the inspection 


\section{Macrothink}

key elements, as identified above (section 0), for the new application, is a primary focus of validation committees (Algernon, 2016).
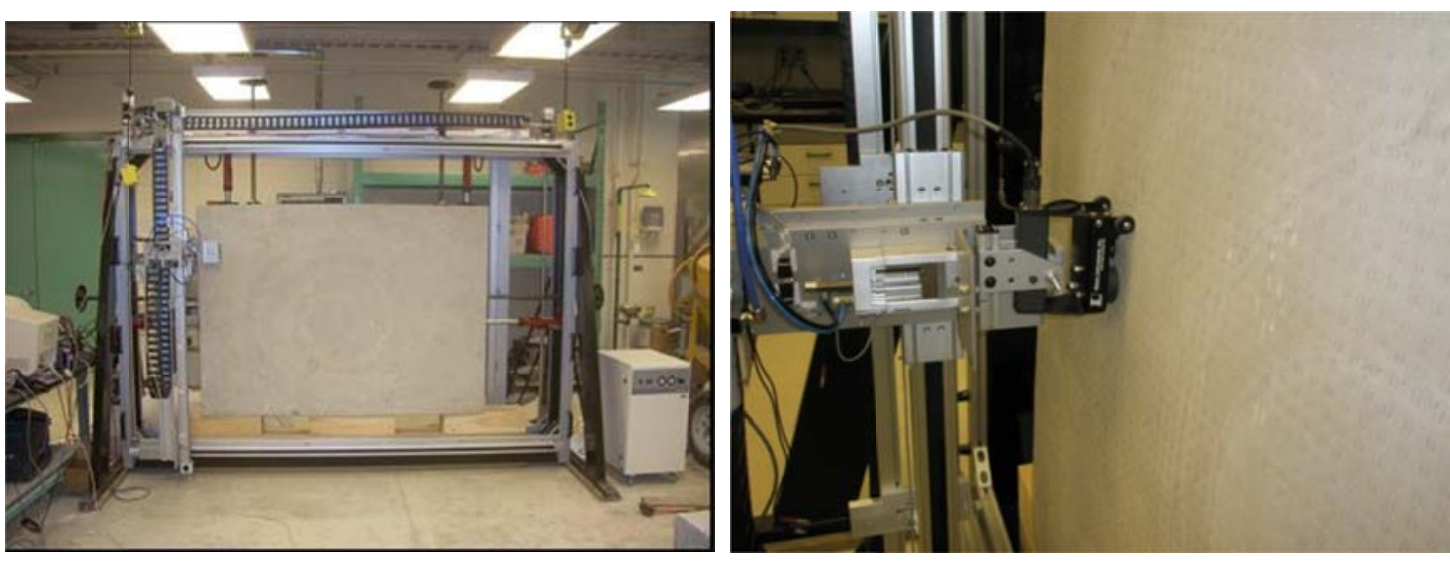

Figure 9. Laboratory Test Frame for automated application of nondestructive testing in civil engineering (NDT-CE)

\section{Conclusion}

A primary application of NDT inspections is the structural integrity assessment of safety-relevant components. In many industries, the information provided by NDT is directly used to judge components regarding their safe operation. Consequently, the reliability of the information provided by NDT inspection systems has a direct effect on the operational safety of a component. Due to the large number of safety-relevant components in the nuclear industry, this industry provides a primary field for the application of NDT. Consequently, strong processes serving to ensure NDT reliability have been established in this industry in terms of qualification systems (e.g. ENIQ). Based on the exact definition of a qualification target and the statistical distribution of trials, quantitative measures for the inspection system reliability are obtained.

Having identified the theoretical assessment of the inspection system functionality and performance by experts as documented in TJ documents according to ENIQ, there is a need to express the outcome of the $\mathrm{TJ}$ in a quantitative way and combine it with the results of the practical demonstration. An approach based on Bayesian statistics is found to be capable, though challenging, since it requires adequate evaluation criteria.

The tool IndEva has been implemented by the Swiss Qualification Body for NDT. It supports the qualification process in providing a detailed statistical evaluation of the practical demonstration and identifying strengths and weaknesses of inspection systems. Furthermore, the TJ quantification approach is covered by the tool and currently analyzed and optimized. The highly-developed NDT qualification process in the nuclear industry can be transferred to other industries, but needs to be adapted to the specific characteristics, needs and resources. In particular, it has been started to transfer the qualification methodology to the relatively new application of advanced NDT in the field of civil engineering (concrete structures). 


\section{References}

Algernon, D. (02 2016). Der Unterausschuss Qualitätssicherung im Fachausschuss ZfP im Bauwesen. DGZfP-Zeitung, S. 8-9.

Algernon, D., Hiltunen, D. R., Ferraro, C. C., \& Ishee, C. A. (2011). NDT Validation Facility at the Florida Department of Transportation. Review of Progress in Quantitative Nondestructive Evaluation Vol. 30A \& 30B. AIP Conference Proceedings, 1335(1), 1448-1455.

ASME American Society of Mechanical Engineering. (2015). Section VI: Rules for Inservice Inspection of Nuclear Power Plant Components. In Boiler and Pressure Vessel Code.

Calmon, P., Mahaut, S., Chatillon, S., \& Raillon, R. (2006). CIVA: An Expertise Platform for Simulation and Processing NDT Data. Ultrasonics, 44(Supplement 1), 975-997.

Dressler, K., \& Trautmann, H. (2010). ENIQ based Qualification of NDE Systems in Small Countries - Example Switzerland. Proceedings of the 8th International Conference on NDE in Relation to the Structural Integrity of Nuclear and Pressurized Components.

Dressler, K., Ernst, H., Scherrer, M., \& Trautman, H. (2009). Qualifizierung von Prüfsystemen für wiederkehrende Prüfungen in Schweizer Kernkraftwerken. Tagungsband der DGZfP-Jahrestagung.

Dressler, K., Ernst, H., Scherrer, M., \& Trautmann, H. (2012). International Acceptance of NDE Qualification Results and Cooperation of National Qualification Bodies. Proceedings of the 9th International Conference on NDE in Relation to the Structural Integrity of Nuclear and Pressurized Components.

Eidgenössische Nuklearsicherheitsinspektorat (ENSI). (2008). Guideline ENSI B07 Sicherheitstechnisch klassierte Behälter und Rohrleitungen: Qualifizierung der zerstörungsfreien Prüfungen. Guideline, Eigenössisches Sicherheitsinspektorat, Brugg (Switzerland).

ENIQ European Network for Inpection and Qualification. (2007). The European Methodology for Qualification of Non-destructive Testing, Third Issue. Brussels-Luxembourg: European Commission.

ENSREG. (2011). EU Stress Tests Specifications. European Nuclear Safety regulators Group.

Erhard, A. (2007). Aufgaben und Abgrenzung der Zerstörungsfreien Prüfung. Proceedings of the DGZfP-Jahrestagung. Fürth (GER).

Gandossi, L., \& Simola, K. (2007). A Bayesian Framework for the Quantitative Modelling Of the ENIQ Methodology for Qualification of Non-Destructive Testing. Petten (NL): European Commission Directorate-General Joint Research Centre (DG JRC), Institute for Energy.

Hiltunen, D. R., Algernon, D., \& Ferraro, C. (2010). Validation of Nondestructive Testing Equipment for Concrete. Gainesville, FL (USA): Florida Department of Transportation.

IAEA. (2014). Safety Classification of Structures, Systems and Components in Nuclear Power Plants. Vienna: IAEA Safety Standards Series. 
IndEva User Manual. (2014). SVTI Swiss Assosication for Technical Inspections.

Jolly, J. A., \& Creighton, J. W. (1977). The technology transfer process: Concepts, framework and methodology. Journal of Technology Transfer, 1(2), S. 77-91.

Mahaut, S., Lonne, S., \& de Roumilly, L. (2006). Validation of CIVA Simulation Tools for Ultrasonic Inspection in Realistic Configuration. Proceedings of the ECNDT 2006. Berlin.

Rosenthal, R. (1966). Experimenter Effects in Behavioral Research. Behavioral Research(8), S. 464ff.

Rössler, G., Trautmann, H., \& Scherrer, M. (2015). Auswahl von geeigneten Testfehlern unter Berücksichtigung der Komponenteneigenschaften, des Schädigungsmechanismus und des ausgewählten ZfP-Verfahrens. Tagungsband der DACH-Jahrestagung 2015,. Proceedings of the DACH Jahrestagung. Salzburg.

Taffe, A. (2008). Zur Validierung quantitativer zerstörungsfreier Prüfverfahren im Stahlbetonbau am Beispiel der Laufzeitmessung (Heft 574) (Bd. 574). Berlin: Beuth Verlag (Dissertation an der RWTH Aachen).

Virkkunen, I., Kempainen, M., \& Ostermeyer, H. P. (2009). Grown cracks for NDT development and qualification. Insight, 51(5), S. 1-5.

\section{Glossary}

NDT: Nondestructive Testing

NDE: Nondestructive Evaluation

NDT-CE: Nondestructive Testing in Civil Engineering, mostly used when referring to concrete structures

ENIQ: The European Network for Inspection and Qualification

TJ: Technical Justification

\section{Copyright Disclaimer}

Copyright for this article is retained by the authors, with first publication rights granted to the journal.

This is an open-access article distributed under the terms and conditions of the Creative Commons Attribution license (http://creativecommons.org/licenses/by/3.0/). 